\title{
Effect of the level of feeding on growth and fat deposition in Large White pigs reared in tropical environment
}

\section{R. CHRISTON}

\author{
I.N.R.A., Station de Recherches de Nutrition, 78350 Jouy-en-Josas
}

The respective effects of tropical climate (compared to a thermoneutral temperature of $17^{\circ} \mathrm{C}$ ) and of a $25 \mathrm{p} .100$ reduction in the level of feeding were studied in Guadeloupe in 52 Large White pigs between $50-80 \mathrm{~kg}$ live weight.

The effect of tropical environment resulted in a significantly lower daily mean gain (-23 p. 100) and feed efficiency (-18 p. 100), but in a 37 p. 100 increase in the internal fat (leaf fat), whereas the amount of subcutaneous fat remained unchanged. Feed intake decreased by 10 p. 100 . As compared to controls, pigs reared in tropical environment exhibited a higher rectal temperature $\left(+1,2^{\circ} \mathrm{C}\right)$ and respiratory rate (multiplied by 3 ), indicating a marked heat stress. The plasma levels of free fatty acids, triglycerides and cholesterol were higher $\left(P^{\prime}<0.10\right)$ in tropical environment, while plasma level of glucose remained unchanged.

The 25 p. 100 reduction in the level of feeding did not modify significantly growth rate and fat deposition. This suggests a marked increase in feed efficiency. This result can be attributed to the metabolic adaptation of the animals to ambient heat and could be of interest for pig production in tropical areas.

\section{Long-term effects of advanced weaning and initial live weight on performance and body composition of the pig. Consequences on the development of the male genital tract}

\author{
B. SEVE, M. BONNEAU \\ I.N.R.A., Station de Recherches Porcines, Saint-Gilles, 35590 L'Hermitage
}

Long-term effects of an advanced weaning (at 12 days of age instead of 23) were assessed in 168 piglets from 28 litters, considering separately the effect of the initial weight ( $\mathrm{L}: 4.22 \mathrm{~kg}, 1: 3.44 \mathrm{~kg}$ at 12 days) and that of sex (entire male and female). As compared to weaning at 23 days, weaning at 12 days caused additional losses $(5.9$ p. 100) because of an aggravation of digestive disorders. Total production length was only increased by 2 p. 100 Feed expenditure to reach $27 \mathrm{~kg}$ live weight was increased by $13 \mathrm{p} .100$. During the growingfinishing period, feed conversion ratio was minimum in initially heavy pigs weaned at 23 days of age and in this weight category. The effect of advancing weaning $(+3.4$ p. 100) was significant $(\mathrm{P}<0.05)$. Parallel, at $100 \mathrm{~kg}$ live weight, the muscle percentage per carcass decreased by 1.9 p. $100(P<0.05)$ and the fat percentage increased by 6.8 p. 100 $(\mathrm{P}<0.01)$. Losses were slightly higher in light pigs than in heavy ones. Feed expenditure to reach $27 \mathrm{~kg}$ live weight was also larger $(+9.3 \mathrm{p}$. 100). When weaning was performed at 23 days, performance of heavy piglets were higher than that of light piglets as well in terms of feed conversion ratio during the growing-finishing period $(-4.5$ p. 100) as in terms of percentage of muscle produced at $100 \mathrm{~kg}$ live weight $(+1.2 \mathrm{p}$. 100). Therefore, the advanced weaning suppressed the superiority of heavy piglets. The effects of the age at weaning or of the initial live weight were identical in both sexes (absence of interaction). As compared to females, entire males gained faster $(+3.7$ p. 100) and exhibited a better feed conversion ratio $(-5.8$ p. 100) as regards the growing-finishing diet. However, their carcass yield was reduced and in spite of a less pronounced fattening level, the percentage of muscle produced was slightly lower $(-1.2 \mathrm{p} .100)$. The age at weaning did not significantly affect the development of the male genital tract. Cowper's glands tended to be more developped at $100 \mathrm{~kg}$ live weight $(\mathrm{P}<0.10)$ in initially light animals. 